\title{
Revisiting Accountability Concept and Practices in Makassar, Indonesia (A Study on 2 Private and Public Hospitals)
}

\author{
Indrianty Sudirman ${ }^{1}$, Andi Indahwaty $\operatorname{Sidin}^{2}$, dan Nurdjanah Hamid ${ }^{3}$ \\ \{indrianty_sudirman@yahoo.com ${ }^{1}$ \} \\ Universitas Hasanuddin, Indonesia ${ }^{1,2,3}$
}

\begin{abstract}
Public and private hospitals have their own characteristics and uniqueness in their management. This research aims to develop an accountability model of public and private hospitals that are able to meet the interests of multi-stakeholders, especially in the era of health service reform. The result shows that the management system in the Public Hospital tends to be systematic and measurable compared to the Private Hospital which tends to be more independent.
\end{abstract}

Keywords: Accountability, Public and Private Hospitals, Health Care Reformation

\section{Introduction}

Hospital accountability is important to accommodate changes and pressures in healthcare reform [1][2][3][4][5], especially with the existence of a national health financing institution whose role is to control accountable health management for multi stakeholders [3][6]. Accountability reporting policies of government agencies are still generic and vertical. Accountability literature is still traditional because it focuses more on vertical accountability and financial aspects, therefore it is less effective in assessing hospital accountability in accordance with the demands of the New Public Management [7][8]. In Indonesia, the adoption of Presidential Regulation No. 12 on National Health Insurance can have implications for hospital quality, ethics, and management. There is no specific and comprehensive mechanism and dimension of accountability assessment for hospitals even though an accountable hospital can provide effective, efficient and equitable health services. Government and private hospitals have their own characteristics and uniqueness in its management. Therefore, it is considered important to compare the accountability measurement model of government and private hospitals in Indonesia. This study aims to develop an appropriate accountability model for government and private hospitals in Indonesia in the era of health service reform. This model is expected to be applied to increase capacity for hospitals in Indonesia, in providing health services that are more effective, efficient and equitable. This will have implications for increasing the competitiveness of hospitals in Indonesia in the global arena, as well as increasing public confidence in hospitals in Indonesia. In addition, the results of this study are beneficial for policy makers and can support the improvement of technological findings in the field of service management science that contribute to society and ensure the achievement of national health development priorities in the field of health and infrastructure by providing accountable health services. 


\section{Method}

The development of hospital accountability models will be carried out through qualitative methods through interviews with various stakeholders related to health. The research instrument used interview guidelines consisting of various questions related to hospital management functions. The research was carried out in 2 public hospitals and 2 private hospitals in Makassar, Indonesia. Data collection was carried out using in-depth interview techniques with Directors, Managers, and Supervisors of public and private hospitals. The respondents chosen purposively based on their management roles and responsibilities in the hospitals. The data in this study can be in the form of words / sentences based on the purpose of the study which is to explore ideas from hospital experts about accountability.

\section{Result and Discussion}

There are many definitions of accountability, but the definition most often used is the definition developed by Mulgan et al. [9], Schedler and Boven [10]. Understanding accountability is synonymous with transparency, equity, democracy, efficiency and integrity [4]. According to Mulgan et al. [9] that the notion of accountability is a concept that continues to develop, and depends on the perspective used. While Schedler [11] explains that accountability is the obligation of government institutions, to inform about what has been done, and emphasizes the capacity of the agency that assesses to impose sanctions on institutions that violate their authority in public service. The practice of accountability in government and private hospitals, can be seen based on the results of the study below:

\subsection{Financial Management}

"We generally arrange financial planning based on proposals from the unit, based on historical data about the realization of the budget in the previous year, and based on the ceiling allocation or budget allocation for the coming year. So, the three bases that become our basis in preparing financial planning" (IS).

"From the unit, then the needs of the unit must be based on the hospital's strategic objectives, after which it is recombined to the head of the field to his field, after that the fields will be collected in each field, after which it will then be collected to each directorate" (AA)

"Bottom up the point" (IS).

Financial management of Public hospitals starts from financial planning which is prepared based on proposals from units/installations, in this case using a bottom-up system. The proposed needs of the units are then filtered out by the heads of related fields and then proposed to each directorate. The reporting system in Public hospitals is done through financial applications and financial reports that are made every month, quarter, and annual BLU organizations tend to be non-profit government organizations in accordance with PP No. 23 of 2005 article 26 states that accounting and financial reports are held in accordance with 
Financial Accounting Standards issued by the Indonesian accounting profession association [12].

While at the Private Hospital, the Respondents stated that:

"Maybe it's a bit different, because the owner of the finance is directly, so the budget is sometimes enough, sometimes not so besides that, you can beg or propose to be fast, because if it is through the bureaucracy, the length is usually slow. Especially so that I don't have to say the possibility of corruption anymore because he is the one to take care of it. Same with drugs, for example, we better have PBF from there, we take it so that there are no suspicious orders. Sponsored messages from pharmacy, for example, how much do you want to give?" (JH).

"If there are incidental ones, well there is also a hospital pharmacy. If drugs have their own responsibility. We trust the pharmacy because on average they can be trusted here for a long time. And I see it is indeed responsible" (JH).

Finance in private hospitals is managed directly by the owner and has a RKAT approved by the director and owner. There is no planning for the procurement of new goods because the company directly includes medicines, which are taken directly from the hospital PBF. For BHP and medical devices, which ones are often used, and for incidental medicines, there is a hospital pharmacy that is self-reliant which is entrusted to the Pharmacy department. For payment, all equipment or medicines taken will be repaid by the hospital. The financial statements are made by accountants and reported directly to the chairman of the PT or owner at the end of each year.

\subsection{Logistics Management}

"The logistics in the hospital now that is running for BHP logistics and the drugs themselves are separate from other logistics. The logistics for stationeries and spare parts are one different system from the drug and BHP system, automatically the planning method is also different from these two groups, namely medicine and BHP are different from logistic management and spare parts. Well, but for the planning method itself, look at it from the previous history with reference to control"'(AA).

"So lately we ask them to make priorities based on the ceiling, well then, they set priorities based on the ceiling, in addition to that priority the amount requested is based on previous history so that for example there is a request, we see why there has to be a spike, is there really a surge in patients, or does it occur guest spikes and so on, is this spike realistic, what's the rationalization? But it is bottom up" (IS).

The logistics management system in the Government Hospital consists of drugs and BHP which have separate systems from stationery, and spare parts so that the planning system used is also different. The planning method is based on history and prioritizes based on the ceiling. When there is demand it will look at why the spike occurred, whether the spike is realistic, and how it is rationalized. Logistics planning is planning the logistics needs of which the implementation is carried out by all potential users (users) then submitted according to the flow that applies in every organization [13]. 
Unlike the case with logistics management in Public hospitals, in private hospitals logistics management is under the director of general administration and finance. The procurement of goods is done through a one-door system through the owner. For distributor or partner selection is also determined by the owner.

\subsection{Human Resource Management}

"Our human resource planning departs from workload analysis, the way we calculate our workload analysis will describe what are the main tasks and functions. So, we divide human resources over those in structural, as well as those in functional" (IS).

Human resource planning in public hospitals is based on workload analysis by describing what are the main tasks and functions. This method starts by setting various effort targets or obtaining estimates of the need for the number of specific types of health workers obtained by dividing the overall effort or health service of the target year by the ability of the types of personnel (Minister of Health Decree No. 81, 2004). After planning and knowing the required number of staff, recruitment, orientation of new employees, and placement of contract staff are then carried out for the next two years. Every two years, there is an employee rotation aimed at developing employee capabilities. Eriksson and Ortega [14] stated through Employee Learning Theory, that job rotation aims as learning for employees because it is an effective way to develop employee capabilities. Rotated employees will gain more knowledge and skills because they face more experience.

After human resource planning and the number of staff needed, recruitment is carried out by the hospital. Through effective recruitment and selection, the organization will get potential employees in accordance with the demands of the job [15].

In contrast to human resource management in public hospitals, human resource management in private hospitals has a different system, respondents stated that:

"Indeed, in principle this is because we are private, so what is said for our public hospitals is not like that. So, we are internal only, develop ourselves in accordance with our own ways. So, in principle, especially private funds, there is no help, unlike the government, there is help. So, we are really based on income. So, we especially for recruiting workers are very limited, not the same as the government, I used to look at the government to get more energy without asking questions first" (JH).

Based on the above statement, it can be concluded that the human resource management of private hospitals is managed internally. Private hospitals do not receive financial assistance, unlike public hospitals that receive financial assistance. Thus, all forms of planning are really based on hospital revenue. When there is a shortage of employees, it is the units or installations that are in demand that there is no planning for recruitment of personnel. If there is a unit or installation that reports, the hospital will call in applicants who have submitted an application file so that recruitment can be done at any time depending on the hospital's needs.

\subsection{Marketing Management}

"In addition to the usual promotion of marketing strategies also maintain existing markets, including BPJS with other coordinated for example insurance then with 
other areas that we keep guarding then marketing also includes cooperation in the field of laboratory examinations, ECG examinations or in fields some are not generally but some are general as well" (IS).

Based on the above statement, it can be concluded that the marketing strategy of the Government Hospital is a promotion, besides that it also establishes collaborations with various parties (figure 1). Then cooperation with the corporation and cooperation with the insurance company that can be established well.

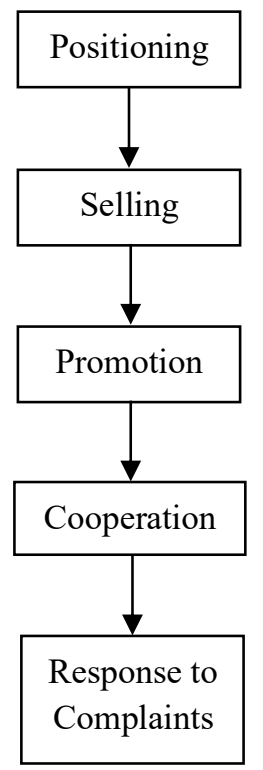

Fig. 1. The Marketing Strategy of the Government Hospital.

Unlike the case with marketing management in Public hospitals, Marketing management in Private Hospitals, respondents stated that:

"Actually, we have ji dok, there is a marketing department, but he's in school so underneath that I just make marketing" (E).

The hospital has a marketing department but it has not run systematically due to lack of human resources. Until now this form of marketing was carried out only through questionnaires given to customers or patients. In line with this, one of the marketing methods allowed according to the Indonesian Ministry of Health is to give questionnaires to the public [16].

To maintain customer loyalty, respondent states that:

"The first certainty is how to speak well with patients. It must be. Communication, maybe doctor. Continue attention. I always tell them that you have to empathize with patients. Don't get angry, you're angry too. How do you feel how the patient feels?" (E). 
So, the hospital trains staff how to behave towards patients, pay attention, and speak well to patients. Hospitals focus on how to provide comfort, attention and the best service to customers. Attention is to give sincere and individual or personal attention given to customers by trying to understand the desires of consumers (figure 2). Where a company is expected to have understood and knowledge about customers, understand customer needs specifically, and have a comfortable operating time.

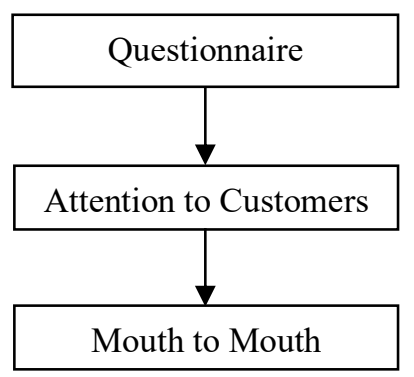

Fig. 2. Maintain Customer Loyalty

\subsection{General Administration}

"Arrange rules or policies. What is clear is that we are not directly making it. Surely at first there was a letter, for example the director of medical services, for example the rules in the service meant the director made a request that this policy or policy would be made and then went into his opinion. The one who issues the letter of decision or policy, there must be a letter of disposition from the leadership to be made because it is the executor. If there is an instruction from the leader to be made, made noodles. Look for anything related to that, usually there is basically a basis for submitting a letter. If the draft has been shown to our leaders, then first, then to the director, if it's finished, or there is a correction, it will be corrected, after it has been issued, its decision letter or policy, and signed by the president director" (WN).

"But it does not rule out the possibility that if suddenly there must be a policy so the results of the leadership's decision. But still we are told that please make this, this is the basis, we still make it but with the leadership's attention" (WN).

"It is not possible for all submissions of policy letters or assignments to be received immediately. They must first be studied. For example, someone asked to make this decision letter first studied with us as the first look and then the head of the field who saw whether this decision letter was really needed or not. If it's really needed, well made it. Usually, it is published more often because there are indeed many filters, if people ask, it is not filled immediately. The point is that the leader still makes the highest decision, may or may not" (WN).

Rules or policies in the Hospital are made based on advice from the directorate. So, it is done by Bottom Up, from the bottom of proposing to make a policy by making a draft that is shown to the head of the field, then submitted to the director. Furthermore, from the director if it has been approved or there is a correction, then it will be corrected and after the acc, a 
decision or policy is issued and signed by the president director. The policies of the direct leadership may be present, but rarely. Usually there is a policy that is decided by the leadership but it is still conveyed to subordinates to make a draft and convey what is the basis so that the policy must exist. All suggestions submitted for a policy will be seen on what basis so that the policy wants to be made, so it is not immediately approved by the leadership. The advice is studied first, seen the basics are valid or not, which is not appropriate will be corrected and corrected and the policy will be published accordingly.

Unlike the case with the management of General Administration in Public hospitals, General Administration management in Private Hospitals Hospital rules and policies are carried out by the President Director and the Director of General Administration and Finance. Arrangement of access to hospital service information including SOPs is also carried out by the director of General Administration and Finance. Then the correspondence flow is carried out from the unit to the staffing for letter numbering and is signed by the director.

\subsection{Patient Safety}

"The concept of patient safety rules is not new. So, it has been implemented since the beginning. Based on this concept, the organizational structure at that time decided that there was a quality and patient safety committee. Because at that time there were only a few people, so only the committee chair with 3 sub divisions also had 3 people there, there were no staff, so at that time we only had a work program with activities. The application of the concept of patient safety is not too complex, the recording is also still very simple through Excel so it's not as complex as it is now" (HAH).

"If the first is the quality and safety division, the accreditation is actually included, if it is evaluated, it is the performance evaluation and other accreditations. If we happen here, the performance appraisal of other units so that in 2014-2017 the division changed into the patient safety division and the accreditation is now changed to the patient quality and safety division. But the concept is actually the same, quality, patient safety and accreditation but the title was changed to the division of quality and patient safety. So, we are also responsible for accreditation" (HAH).

"If based on the standard of committee of hospital accreditations, especially the quality enhancement and patient safety working group, it is not stated what the graduates are, but the principle is that it has been determined there at the quality enhancement and patient safety working group, if the committee chaired us is not a committee but a unit, the chair of the quality assurance unit must be a doctor. The philosophy behind it must be that the doctor because there are many medical indicators that we must monitor and must validate it is the background to the chairman must be a doctor. If the division does not have a special division, in principle, people who have received special training directly from the hospital accreditation committee as TOT and certified are valid every 2 years, we must recertify again because every year there are many changes to the hospital accreditation committee" (HAH). 
"Yes, if it happens to be a coincidence after the rotation in March, there is the chairman of the rotational quality assurance unit, the staff of the quality division and the safety of patients also rotating, so they must re-train. Well, we are temporarily waiting for the schedule from the time when there will be training because every year there are on average 2 or 3 times a year, so the training cannot be predicted when it depends on the invitation, because we are waiting" (HAH).

The concept of patient safety has been applied since the beginning and based on that concept a quality and patient safety committee was formed with 3 subdivisions namely the Patient Safety, Quality and Accreditation division which has now been changed to the Patient Quality and Safety division, infectious control center division, environmental health and safety occupational safety division. Based on the quality enhancement and patient safety working group, the qualifications of the head of the quality assurance unit must be doctors because there are many medical indicators that must be monitored and validated. In principle, division staff are those who have received special training directly from the hospital's accreditation committee as term of reference and are certified for 2 years. So, every 2 years must be certified or after the rotation of new staff must undergo retraining.

Unlike the case with Quality Management and Patient Safety in Public hospitals, Private Hospitals have a quality committee and are currently focusing on managing hospital accreditation.

\section{Conclusion}

1) Financial management of public hospitals starts from financial planning prepared based on proposals from units / installations, in this case using a bottom up system. The proposed needs of the units are then filtered out by the heads of related fields and then proposed to each directorate. The reporting system in hospitals is carried out through financial applications and financial reports that are made monthly, quarterly and annually. Meanwhile in private hospitals, financial management is handled directly by the owner who has been previously approved by the Director and owner of the foundation. The financial reporting is reported directly to the chairman of the foundation or owner at the end of each year.

2) The logistics management system in a government hospital consists of drugs and BHP which are separated from stationery, ART, and spare parts. The planning methods used are based on history and prioritization. Meanwhile for logistics management in private hospitals, the procurement of goods until the selection of partners is carried out fully and determined by the owner of the foundation.

3) Human resource planning in public hospitals is based on workload analysis by describing what are the main tasks and functions. After planning and knowing the required number of staff, recruitment, orientation of new employees, and placement of contract staff are then carried out for the next two years. While the human resource management system in a private hospital does not require planning at all but depends on the demand for units or installations when there is a shortage of personnel caused by employees leaving or stopping work. The recruitment system is also not publicly announced, but applicants only submit application files and wait for interview calls at any time when the hospital requires additional staff. 
4) The marketing strategy of public hospitals is carried out by promotion, establishing cooperation with various institutions, and insurance companies. Hospital marketing activities only occur accidentally and not by design. Although the marketing strategy has not functioned well, improvements continue to be made because currently most of the hospital's market share is BPJS patients. While in private hospitals, the hospital has not yet focused on conducting large-scale promotions but instead is working to improve the quality of services in order to create a good image in the community.

5) General administration related to rules or policies in public hospitals is made based on the advice of the directorate, in this case employees in the unit or installation make a draft proposal then corrected by the head of the field and then submitted to the President Director for approval. Regarding the flow of correspondence, although there are no detailed SOP, in general, all incoming and outgoing letters must be with the knowledge of the President Director or directors of the relevant directorates. While in private hospitals, administrative management is generally carried out and approved by the President Director and the Director of General Administration and Finance. Arrangements regarding access to information and SOP for services in hospitals are carried out by the Director of General Administration and Finance. The correspondence flow made by the unit or installation is brought to the personnel department for numbering of letters and then signed by the President Director.

The concept of patient safety in public hospitals is implemented by holding the principle that quality and patient safety in hospitals is a shared responsibility so that everyone in the hospital understands the importance of patient safety and quality of service. While in private hospitals, although currently has a quality committee, the staff in the quality committee is focusing on meeting hospital accreditation standards so there is no systematic flow regarding the application of hospital quality management concepts.

\section{References}

[1] L. D. Gamm, "Dimensions of accountability for not-for-profit hospitals and health systems.," Health Care Manage. Rev., vol. 21, no. 2, pp. 74-86, 1996.

[2] E. J. Emanuel and L. L. Emanuel, "What is accountability in health care?," Ann. Intern. Med., vol. 124 , no. 2 , pp. $229-239,1996$.

[3] N. Daniels and J. Sabin, "The Ethics Of Accountability In Managed Care Reform: Recent efforts at reforming managed care practices have one thing in common: a call for accountability to consumers.," Health Aff., vol. 17, no. 5, pp. 50-64, 1998.

[4] D. W. Brinkerhoff, "Accountability and health systems: toward conceptual clarity and policy relevance," Health Policy Plan., vol. 19, no. 6, pp. 371-379, 2004.

[5] S. Timmermans, "From autonomy to accountability: the role of clinical practice guidelines in professional power," Perspect. Biol. Med., vol. 48, no. 4, pp. 490-501, 2005.

[6] J. W. Rowe, "Pay-for-performance and accountability: related themes in improving health care," Ann. Intern. Med., vol. 145, no. 9, pp. 695-699, 2006.

[7] B. Jessop, "The rise of governance and the risks of failure: The case of economic development.," Int. Soc. Sci. J., vol. 50, no. 155, pp. 29-45, 1998.

[8] T. Erkkilä, "Governance and accountability-A shift in conceptualisation," Public Adm. Q., pp. $1-38,2007$.

[9] R. Mulgan, “Accountability’: An ever-expanding concept?,” Public Adm., vol. 78, no. 3, pp. 555-573, 2000.

[10] N. W. Sobe and D. T. Boven, "Nineteenth-century world's fairs as accountability systems: Scopic systems, audit practices and educational data," Educ. Policy Anal. Arch., vol. 22, p. 118, 2014. 
[11] A. Schedler, "Conceptualizing accountability," self-restraining state Power Account. new Democr., vol. 13, p. 17, 1999.

[12] T. Irawan, "Technical Management and Financial Reporting of Hospitals as a Public Service Agency (BLU),” 2014. [Online]. Available: https://trikuris.wordpress.com/2014/12/11/teknispengelolaan-dan-pelaporan-keuangan-rumah-sakit-sebagai-badan-layanan-umum-blum.

[13] B. Arraniry, Analysis of Non-Medical Logistics Planning in Sub-Divisions of the Household General Hospital Fatmawati Center. Depok: University of Indonesia, 2012.

[14] T. Eriksson and J. Ortega, "The adoption of job rotation: Testing the theories," Ilr Rev., vol. 59, no. 4, pp. 653-666, 2006.

[15] V. Rivai, Islamic human capital: dari teori ke praktik manajemen sumber daya Islami. Rajawali Press, 2009.

[16] M. Sujana; Nurwandi, "Marketing Strategy Analysis in Marketing Case Study Service Products at Karya Bhakti Hospital,” Ranggagad. Sci. J., vol. 9, no. 2, pp. 137-147, 2009. 